PNI.-2672

UC-11

\title{
Isolation of Plutonium
}

Physical-Chemical States from Natural Waters

Wafter C. Weimer

August 1978

Prepared for

Rockwell Hanford Operations

A Prime Contractor for the

U.S. Department of Energy

under Contract EY-T7-C-06-1030

Pacific Northwest Laboratory

Operated for the U.S. Department of Energy by 
This report was prepared as an zccount of woth sponjored by the United States Covernment. Neither the United States nor the Department of Energy, nor any of their employees, nor any of their contracteri. subcontractorn, or their employees, makes any watranty, express or implied, or assumes any legal liability or responsibility for the accuracy, completeness or usefulness of any iniormation, apparatus, product or pracesi disclosed, or represents that its use would not intringe privately owned rights.

The views, opinions and conclusions contained in that reporf are thost of the contractor and co nat decessarily represent those of the United States Covernment or the United States Deparment of Energy-

\author{
PACIHC NORTHWEST LABORATORY \\ operated by \\ BATTELLLE \\ for the \\ UNITED STATES DEPARTMENT OF ENERGY \\ Under Contract EY-76-C-26-1230
}
Prioled in thit U-iated States of America
Avalabie from
Nutional Tecrn cal information Senice
Unised Sares Departinent of Conmerce
Szws Rort Royal Rosd
springreid, Virginia 22131

Price: Pinted Copys 2: Nisteficie 5306

\begin{tabular}{|c|c|}
\hline *Pagrs & $\begin{array}{l}\text { Nris } \\
\text { Wefling Price }\end{array}$ \\
\hline$x n-2 z$ & $\sin$ \\
\hline 026.058 & 34.50 \\
\hline $551-045$ & 5325 \\
\hline$a r s-100$ & 5500 \\
\hline $101-195$ & $15 \div 0$ \\
\hline $125-112$ & 5725 \\
\hline $15 \mathrm{~N}-175$ & $2 x$ \\
\hline $176-200$ & 596 \\
\hline $301-225$ & 39.25 \\
\hline $231-20$ & 53.50 \\
\hline 31.25 & 570.75 \\
\hline $27+369$ & Bri:ces \\
\hline
\end{tabular}


33679000493116

ISOLATION OF PLUTONIUM PHYSICAL-CHEMICAL STATES FROM NATURAL WATERS

Walter C. Weimer

August 1978

Prepared for

Rockwe 11 Hanford Operations

A Prime Contractor for the

U.S. Department of Energy

under Contract EY-77-C-06-1030

Pacific Northwest Laboratory

Richland, Washington 99352 
. 


\section{CONTENTS}

SUMMARY

INTRODUCTION 2

EXPERIMENTAL METHODS

RESULTS AND DISCUSSIONS

Removal of Particulate Materials 8

Use of Sorption Materials to Remove Soluble Plutonium 9 Species

Use of Ion Exchange Resins to Remove Soluble Plutonium 10

Concentration of Individual Plutonium Species 11

Concentration of Ali Plutonium Species $\quad 12$

Field Testing the Large Volume Water Sampling 13

Methodology

$\begin{array}{ll}\text { CONCLUSIONS } & 13\end{array}$

RECOMMENDATIONS $\quad 14$

$\begin{array}{ll}\text { ACKNOWLEDGMENTS } & 16\end{array}$

$\begin{array}{ll}\text { REFERENCES CITED } & 17\end{array}$ 


\title{
ISOLATION OF PLUTONIUM PHYSICAL-CHEMICAL
}

STATES FROM NATURAL WATERS

\author{
Walter C. Weimer \\ Physical Sciences Department
}

Pacific Northwest Laboratory

Richland, Washington 99352

Operated by Battelie Memorial Institute

\section{SUMMARY}

The purpose of this research program was to evaluate the feasibility, on a bench scale, of methods for preconcentrating, selectively, individual plutonium forms from very dilute natural water samples, and to apply these results to use with the Battelle large volume water sampler. From the results of the current investigations, several alternative water sampling strategies have been recommended. The preferred water sampling technique has been field tested at severai groundwater wells in the 200 East and 200 West areas of the U. S. Department of Energy Hanford Reservation.

These laboratory investigations, in combination with field testing of the proposed water sampling techniques, have yielded the following conclusions:

1) The use of polypropylene microporous filters (0.04 pore size) in con-

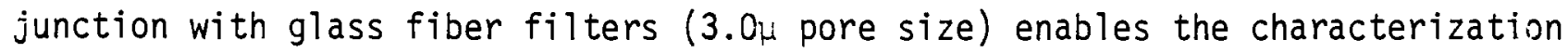
of two size fractions of particulate plutonium forms in groundwater samples. Those species which pass the microporous poiypropylene filters are considered to be in solution.

2) The sorption and ion exchange media evaluated do not show the selectivity necessary to allow preconcentration of individual plutonium forms from natural water samples by any of these media beds under the conditions evaluated.

3) $\mathrm{Al}_{2} \mathrm{O}_{3}$ is the most effective sorption media that was examined for removing any plutonium species from natural water samples at neutral $\mathrm{pH}$ values.

On the bases of these investigations, a standard field testing methodology has been proposed for sampling ground waters near nuclear waste management areas. 
Additional laboratory evaluations of plutonium species interactions with sorption and ion exchange media have also been recommended.

\section{INTRODUCTION}

Minute quantities of plutonium may be in the natural waters, both surface waters and ground waters, in areas immediately adjacent to nuclear waste management or nuclear processing plants. While these plutonium isotopes may be present in concentrations of only femtocuries to picocuries per liter, the determination of these concentrations and the characterization of the chemical and physical forms of plutonium in the waters may provide important information on the plutonium sources. This information may, in turn, be related to the potential for plutonium migration from a waste burial or waste disposal site. Because of the very low concentrations of plutonium found in these waters, particularly in ground waters, ordinary sampling techniques which collect a few liters or less of sample do not provide adequate amounts of plutonium to quantify. The limit of detection for gross alpha activity in a one-liter water sample is typically about 20 picocuries per 1 iter. In addition, such small water samples may not contain a large enough quantity of plutonium to be separated into its different physical and chemical forms. Therefore, it is highly desirable to have a standardized methodology for sampling large volumes of ground water to obtain information on the size of plutonium-containing particles in the water, the concentrations of plutonium on these particles, and the concentration and species identification of the soluble plutonium forms present in the water. The laboratory studies performed as part of this research were to evaluate the feasibility of several different methods for the potential preconcentration of plutonium forms from naturai water samples. Furthemore, these techniques have been tested in field application situations.

Liquid waste disposal facilities in the vicirity of the 234-5 building in the 200 West area of the $\mathrm{J}$. S. Department of Energy Hanford Reservation in Wasinington have been used for the disposal of actinide waste streams to the ground. Over a period of several years these trenches have generally received very large quantities of water $\left(10^{7}\right.$ to $10^{9}$ liters) which have contained some small concentrations

of plutonium. (1) These volumes of radioactive waste were disposed a few feet below the surface of the ground. Surrounding each of these disnosal trenches is a series of monitoring wells which are drilled to the groundwater table at the depth of $>200$ feet below the ground surface. These wells have been sampled routinely and have yielded values of $\leq 20 \mathrm{pci} / \mathrm{e}$ of total gross alpha activity. While this 
information by itself satisfies all requirements that radiological health restrictions might set, these upper limit estimates for gross alpha activity are useless for evaluating potential low level contamination or migration trends over long time intervals. In addition, these past analyses have provided no information on the physical and chemical states of plutonium in solution; information on plutonium form is absolutely essential for an evaluation of the reasons for the presence of plutonium in a water and what its further migration potential may be.

The significance of the specific physical or chemical forms of plutonium in groundwater solutions has been emphasized by investigations of the migration of plutonium observed in ground waters at two other radioactive waste burial locations, a commercial site at Maxey Flats, Kentucky, and at a site at Oak Ridge National Laboratory. $(2,3)$ Although the plutonium buried as wastes at these locations had been anticipated to remain immobilized by interactions with soil constituents, easily detectable quantities of plutonium have, in fact, migrated several hundred yards at both locations. The plutonium migration at Oak Ridge National Laboratory from the waste burial ground and into White Oak Lake has been identified as due to migration of a $\mathrm{Pu}(V I)$ species. (3) This $\mathrm{Pu}$ species is known to be much more mobile than the more commonly occurring $\mathrm{Pu}$ (IV) due principally to different hydrolysis and complexation constants. $(4,5)$ The identification of this inorganic plutonium form which was traveling with the ground water has provided a starting point for assessing future migration potentials at these sites. In addition, Wilhite has recently reported the migration of an organic-plutonium complex, tributyiphosphate-Pu, in laboratory experimental systems. (6) Under conditions using premoistened soil, the TBP-Pu complex did not interact strongiy with the soil constituents but traveled predominantely with the flow of the water. Weiss, et al., have also reported on the complex organic make-up of several trench waters from the Maxey Flats site and have suggested the significance of the organic species in effecting transuranic migration. (7) The results of these studies at other sites emphasize (a) that some forms of plutonium are clearly more readily mobilized under certain environmental conditions than other forms, and (b) that some identification of the physical or chemical forms of plutonium in the waters can provide additional information necessary for interpreting transuranic movement in ground waters and the potential for additional transuranic migration. Thus, the characterization of the physicai and chemical nature of piutonium forms in natural waters can provide valuable data required for the management of ground waters in and around nuclear waste handling facilities. 
There are two different approaches which have been used to characterize the nature of plutonium forms in natural waters. The first of these techniques involves the determination of plutonium oxidation states in the water sample. (3) This procedure uses either selective extraction or precipitation techniques to differentiate between $P u(I I I), P u(I V)$ and $P u(V I)$. The extraction or precipitation may follow a prefiltering of the water sample to differentiate between the particulate $\mathrm{Pu}$ and the soluble $\mathrm{Pu}$. This method suffers predominantely from the inability to detect sub-pCi/l concentrations of plutonium unless enormous water volumes are concentrated by evaporation. It may work very effectively in situations where the plutonium concentrations are $\mathrm{pCi} / \mathrm{l}$ or greater. At lower concentrations than this, it is not feasible to collect and solvent extract or co-precipitate the plutonium from the very large quantities of water that would be required.

The second approach to the determination of very low concentrations of plutonium in natural waters has involved preconcentration of the soluble plutonium species onto ion exchange media. $(8,9)$ This method, in which large quantities of the water sample are passed through ion exchange beds or sorption beds, is i imited only by the self-imposed time restriction on water pumping. This approach generally uses a prefilter to remove some predetermined size of plutoniumcontaining particulate materials and then fractionates the soluble plutonium species according to their charge characteristics, that is, according to their cationic or anionic characteristics. This is a valuable approach because it is known empirically that anionic species tend to migrate in soil solution much more readily than do cationic species; (10) however, this technique does not provide information concerning the oxidation states of the plutonium species. In addition, under some natural water conditions, the author has found that the proportion of plutonium in the anionic and cationic forms is dependent upon the order in which the water sample is passed through the anion exchange resin and cation exchange resin beds. If ion exchange were the only processes affecting plutonium removal onto these resins, then the anionic and cationic ratios for the total plutonium concentration in the water sample should remain unchanged regardless of the order of the ion exchange beds through which the water was passed. Since this is not always observed, there is some uncertainty regarding the nature of a portion of the plutonium that is removed by the ion exchange resins.

An improved fractionation technique for characterization of plutonium forms in natural waters would be one providing information on both the plutonium valarce 
states and the ionic character of the soluble plutonium species. However, such a technique is not economically readily available. Alternatively, we sought to determine the feasibility of utilizing the different sorption and/or ion exchange properties of various solid media to remove different individual plutonium oxidation states from natural water samples when these solid media were used in the Battelle large volume water sampler. This use allows the sampling of the very large water volumes required to analyze sub-pCi/l levels of plutonium. This laboratory study was to evaluate the selectivity of a variety of solid media for removing individual plutonium species from natural water samples and to apply the laboratory techniques on a broader basis to sampling natural waters in and around nuclear waste management areas.

The specific objectives of the research included:

1) Evaluate several types of sorption media and ion exchange resins as substrates for preconcentration of individual plutonium species from very dilute natural water solutions.

2) Determine the suitability of microporous polypropylene filters for field use as a technique to remove very fine plutonium-containing particulate materials that are not filtered out with a normal $3.0 \mu$ filter.

3) Recommend several alternative sampling methodologies for natural water solutions containing very dilute concentrations of plutonium species and rank these methodologies according to specific purpose.

4) Fieid test the preferred standard methodology for groundwater sampling in the 200 East or 200 West area of the U. S. Department of Energy Hanford Reservation.

\section{EXPERIMENTAL METHODS}

The technique used for preconcentrating traces of transuranic elements from natural water solution employs the Battelle large volume water sampler. (12) This sampler contains a series of filters to remove particulate materials from the water sample prior to passage of filtered water through a series of beds of collection media (Figure 1). These media may be either ion exchange resins or sorption media which remove some or all of the transuranic species which have passed through the filters. These media retain the filtrable species by a combination of chemical phenomena including entrapment, adsorption, absorption, precipitation, and ion exchange. This technique to collect and concentrate trace quantities of radio-. nuclides has been used with sea water, (12-14) Columbia River water, (15) reactor 
effluent waters, $(10,16)$ and freshwater ponds. $(8,17)$ when this sampler is used under field conditions, the influent water enters the sample from a high pressure pump. The water effluent from the large volume water sampler is passed through a volume recording water meter. The principal limitations in the volume of water sampled by this technique is the time alloted for sampling. However, high turbidity water samples may cause a premature plugging of the filters and limit the water sample volume. Generally, however, several hundred gallons of water are pumped through this sampler and the trace concentrations of radionuclides are removed from the water sample onto the series of filters and the sorption media or ion exchange beds.

We sought to determine the most effective sorption media for removing soluble plutonium species from groundwater solutions. Previous studies evaluating isotope retention efficiencies had not evaluated the ability of various media to retain plutonium. Twenty different sorption media were evaluated in this laboratory investigation. The ability of six different ion exchange resins to retain individual plutonium species from groundwater solutions was also determined.

Four different physical/chemical forms (three different oxidation states) of plutonium were prepared for studying the interactions with sorption media and ion exchange resins. The techniques used for these plutonium oxidation state adjustments were from those discussed by cleveland. (18) No attempts were made to confirm the actual oxidation state of the plutonium species produced by each of the methods described below.

$\mathrm{Pu}^{+3}$. The $\mathrm{Pu}^{+3}$ was prepared by the reaction of the $\mathrm{Pu}^{+4}$ stock solution with $0.2 \underline{\mathrm{N}} \mathrm{NH}_{2} \mathrm{OH} \cdot \mathrm{HCl}$ in $4 \underline{\mathrm{N}} \mathrm{HNO}_{3}$. This reaction was allowed to proceed at room temperature with continual stirring for approximately 60 minutes. The reaction is reported to be complete in five minutes.

$\mathrm{Pu}^{+4}$. The plutonium isotope as received from the Isotopes Laboratory of Oak Ridge National Laboratory was reported to be in the +4 oxidation state. The stock solution was stored in $4 \mathrm{~N} \mathrm{HNO}_{3}$ with excess $\mathrm{NaNO}_{2}$ added. In the presence of $\mathrm{HNO}_{3} \mathrm{NO}_{2}-$ is reported to oxidize $\mathrm{Pu}^{+3}$ to $\mathrm{Pu}^{+4}$ and to reduce $\mathrm{Pu}^{+6}$ to $\mathrm{Pu}^{+4}$ urider these experimental conditions.

$\mathrm{Pu}^{+6}$. $\mathrm{Pu}^{+6}$ was prepared from the $\mathrm{Pu}^{+4}$ stock solution by oxidation with excess $\mathrm{HClO}_{4}$. Equal volumes of the plutonium stock solution in $4 \mathrm{~N} \mathrm{HNO}_{3}$ and concentrated $\mathrm{HClO}_{4}$ were mixed and heated to perchlorate fumes for approximately 90 minutes. Additional $\mathrm{HClO}_{4}$ was added as necessary. The oxidation of the $\mathrm{Pu}^{+4}$ to yield $\mathrm{Pu}^{+6}$ in concentrated $\mathrm{HClO}_{4}$ is reported to be quite rapid. 
$\mathrm{Pu}^{+4}$ Colloid. An aliquot of the $\mathrm{Pu}^{+4}$ stock solution was added to a neutral groundwater solution, readjusted to $\mathrm{pH} 7$, and allowed to sit for approximately 60 days. At that time, this solution was filtered through an Amicon ultrafilter with a nominal molecular weight cutoff of 10,000 MWU. The purpose of this ultrafiltration step was to provide some characterization of the nature of the $\mathrm{Pu}^{+4}$ hydrolysis products in solution. Those species with the size of greater than 10,000 molecular weight units were removed. The plutonium forms passing through the ultrafilter were used for the colloid-sorption media and colloid-ion exchange resin interaction studies.

A ${ }^{237} \mathrm{Pu}$ radioisotope tracer was used during these laboratory investigations. (The concentrations of ${ }^{237} \mathrm{Pu}$ used during these investigations was $210^{-13} \mathrm{M}$.) This plutonium isotope (half life 45.6 days) decays almost exclusively by electron capture and emits a series of gamma rays at 97, 101, $114 \mathrm{keV}$ associated with the electron capture process. The use of this isotope allows the direct quantification of the plutonium by instrumental counting without the prior chemical separation, ion exchange, and electroplating steps which would be required for normal alpha energy analysis. The ${ }^{237} \mathrm{Pu}$ isotope was quantified by counting on a standard $\mathrm{Ge}(\mathrm{L} i)$ diode system.

The interactions of these oxidation state-adjusted plutonium species with sorption media and ion exchange resins were performed using freshly collected, filtered ground water. This water was obtained from a well located on the Yakima River flood plain in Richland, Washington, from a depth of approximately 250 feet below the ground surface. The prepared plutonium species were added to a $500 \mathrm{~m} 1$ aliquot of this ground water, readjusted to neutral pH when necessary, and passed through the sorption media or ion exchange resins within 15 minutes from the time of preparation. These solid media were packed in $1 \mathrm{~cm}$ diameter ion exchange columns to a depth of $2.5 \mathrm{~cm}$. Twenty-five $\mathrm{ml}$ aliquots of the spiking solutions were passed through these media at flow rates which ranged from $3-65 \mathrm{ml} / \mathrm{m} / \mathrm{cm}^{2}$. (The variations in flow rate were a function of the particle size of the sorption or ion exchange media and apparently did not affect the proportion of plutonium retained by the media.) The effluents from these columns were collected in polyethylene bottles. Immediately following passage of the ${ }^{237} \mathrm{Pu}$ spiked solutions through the columns, $25 \mathrm{ml}$ of unspiked ground water was passed through the columns as rinsing solution. These rinsing solutions were collected in separate poiyethelyne containers. All samples were acidified with concentrated $\mathrm{HCl}$ immediately after collection to prohibit plutonium precipitation or sorption onto the surface 
of the bottles before instrumental quantification. A materials balance for ${ }^{237} \mathrm{Pu}$ was performed for each of the different sorption studies. The average overall ${ }^{237} \mathrm{Pu}$ recoveries were excellent and ranged from approximately 93.5-99.5\%.

\section{RESULTS AND DISCUSSION}

The research in this program was divided into three laboratory tasks and a phase of field testing wich integrated the findings of the laboratory phases of the research. Each of these individual research aspects is discussed below;

\section{REMOVAL OF PARTICULATE MATERIALS}

Previous applications of the Battelle large volume water sampler have used glass fiber filters with a nominal pore size of $3 \mu$ to remove coarse particulate matter from water samples. Since filters of this pore size allow passage of small particles, it was desired to obtain high-flow, small pore size filters to remove many of these smaller particles from groundwater solutions. A better size differentiation of particulate matter in well waters will allow the determination of whether plutonium species passing the glass fiber filters are truly soluble materials and an assessment of whether small, Pu-bearing particles may be moving through aquifiers.

Several Celgard microporous polypropylene filters manufäctured by the Celanese Chemical Company were evaluated for use supplementing the $3 \mu$ glass fiber filters in the large volume water sampler. Simple laboratory column studies with both $0.02 \mu$ and $0.04 \mu$ pore size Celgard filters manufactured with two different chemical binders indicated that either of the $0.04 \mu$ filters (No. 5510 and No. 5511) provided flow rates which were the most suitable for field use. Extrapolated estimates of the total flow rates that could be achieved with each celgard filter type in the large volume water sampler based upon these in-lab tests are presented in Table 1.

To obtain an estimate of how rapidly these microporous filters would become plugged by small particles under actual operating conditions, a large volume water sampler fitted with both $3.0 \mu$ glass fiber and $0.04 \mu$ microporous filters was attached to the 329 Building water supply system. In this test, we were able to pass approximately 4,000e of water through this filter series without experiencing any clogging. Field tests at actua? wells have demonstrated that. while flow rates are less than observed during this building test, the microporous polypropylene Celgard filters can be applied successfuliy to achieve size fractionation 
of particulate materials in groundwater samples. The use of water pumps capable of producing 80 p.s.i., together with large volume water samplers constructed to reduce leakage effects, provides the maximum in-field flow rates.

The use of two sets of filters--a $3 \mu$ and a $0.04 \mu$ pore size--in the large volume water sampler for well samplings, provides a much better size fractionation of the particulate species in these groundwater samples than has been available before.

\section{USE OF SORPTION MATERIALS TO REMOVE SOLUBLE PLUTONIUM SPECIES}

Twenty sorption media with different physical properties and varying surface properties were evaluated to determine if very dilute concentrations of individual plutonium species could be selectively preconcentrated by these solid matrices. These media were chosen to include (1) materials with a very high surface area per gram of solid, (2) different particle sizes, and (3) different chemical pretreatments for some of the solid materials.

Three different plutonium oxidation states and a Pu-colloid sample were prepared and were interacted with the solid matrices individually. The percent of the total feed of each plutonium solution that was retained by the individual sorption media is shown in Table 2. From these data, it can be seen that by far the best adsorbents for removing all four of these plutonium forms from natural water solutions are the $\mathrm{Al}_{2} \mathrm{O}_{3}$ materials. Approximately 85 to $90 \%$ of the $\mathrm{Pu}^{+}, \mathrm{Pu}^{+}$, and $\mathrm{Pu}^{{ }^{+}}{ }_{4}$-colloid in the feed solutions was retained by one passage through the $2.5 \mathrm{~cm}$ thick beds of $\mathrm{Al}_{2} \mathrm{O}_{3}$. The percent retention for the $\mathrm{Pu}^{+}{ }_{6}$ was somewhat higher. Essentially all of the $\mathrm{Pu}^{+}{ }_{6}$ in the feed solutions was retained by the $\mathrm{Al}_{2} \mathrm{O}_{3}$ beds. This difference between the retention of the +6 oxidation state and the other plutonium oxidation states was the largest and most reproducible plutonium retention efficiency difference seen for any of the sorption media evaluated. The retentions of the plutonium species by the other sorption media were considerably less than the $\mathrm{Al}_{2} \mathrm{O}_{3}$ retention and were also unselective for individual plutonium forms. These data indicate that either the individual $\mathrm{Pu}^{+3}, \mathrm{Pu}^{+4}, \mathrm{PuO}_{2}^{+2}$ ions and $\mathrm{Pu}^{+4}$-colloid species are all retained with approximately the same efficiency by each of these media or that the different plutonium oxidation states interact rapidly with inorganic ions in the groundwater sample to form similar inorganic complexes (mostly singly or doubly charged) which control the sorption behavior of the plutonium forms. This appears to be the probable fate of the oxidation state-adjusted plutonium species. If these inorganic complexes have similar 
charge densities, they would interact with the sorption media to approximately the same degree regardless of the actual plutonium oxidation state originally added to the groundwater solutions.

Theoretical studies $(19,20)$ have proposed several Pu-inorganic ion complexes that would be soluble, stable species under environmental conditions quite similar to the conditions prevailing during these laboratory studies. The dominant species predicted by these modeling efforts are generaliy singly or doubly charged carbonate, hydroxide, or mixed carbonate-hydroxide complexes of Pu(III), Pu(IV), or $\mathrm{Pu}(\mathrm{VI})$. In addition, Alberts, et al., (9) have reported that the dominate soluble plutonium form in Lake Michigan waters is anionic and have speculated that this form is a carbonate complex of Pu(IV). These studies support the supposition that the plutonium species interacting with the various sorption media in this study were partial hydrolysis products or other inorganic ion complexes of the prepared plutonium oxidation states and suggest, further, that the formation of these complexes is very rapid under near neutral conditions in natural waters. The formation of these complexes can account for the relatively non-selective interactions with the sorption media which were observed. The major conclusions from these laboratory evaluations with well-defined plutonium species and well-defined sorption media are:

1) These media are relatively unselective toward retention of any individual forms. Therefore, it does not appear to be possible to preconcentrate selectively individual plutonium oxidation states from neutral groundwater solutions using any of the sorbent media that were tested.

2) $\mathrm{Al}_{2} \mathrm{O}_{3}$ materials are the most efficient sorption media for removing from neutral groundwater solutions trace concentrations of all plutonium valence states evaluated. This is quite encouraging because it provides greater creditability for previous data which have been obtained using $\mathrm{Al}_{2} \mathrm{O}_{3}$ beds for plutonium preconcentration from natura? waters. These results also indicate that no significant fraction of the prepared plutonium species passed through a single $2.5 \mathrm{~cm}$ thick $\mathrm{Al}_{2} \mathrm{O}_{3}$ bed.

\section{USE OF ION EXCHANGE RESINS TO REMOVE SOLUBLE PLUTONIUM SPECIES}

Studies with the 20 sorption media provided information regarding which of these materials were effective for removing all plutonium species from solution. However, since no material was selective enough for our requirements, we also 
evaluated the use of ion exchange resins as (a) selective preconcentrators of plutonium species or as (b) non-selective preconcentrators which would selectively release individual plutonium species when eluted with varying concentrations of acid. The data for the overall retention of the individual plutonium species by six ion exchange resins from groundwater solutions at neutral pH values and groundwater solutions adjusted to $\mathrm{pH} 2$ are presented in Table 3 . The resins that were evaluated include a standard cation resin ( $A G-5 \mathrm{CW}-\times 44$ ) in both the $\mathrm{Na}^{+}$and $\mathrm{H}^{+}$forms, a macroporous cation resin $(A G M P-50)$ in both the $\mathrm{Na}^{+}$and $\mathrm{H}^{+}$forms, a macroporous anion resin (AG MP-1) in the $\mathrm{Cl}^{-}$form, and a standard anion resin $(A G 1-X 4)$ in the $\mathrm{Cl}^{-}$form.

\section{Concentration of Individual Plutonium Species}

It is anticipated that the plutonium species being loaded from the groundwater solution onto the ion exchange resins would be retained most effectively by the cation resins if the plutonium species were in a cation form. This behavior was observed when the $\mathrm{pH}$ of the groundwater feed solution was adjusted to $\mathrm{pH} 2$ prior to passage through the ion exchange columins and also when the cation resins were used in the $\mathrm{H}^{+}$form. (This latter type of interaction was due to an overall lowering of the $\mathrm{pH}$ of the feed solution by the resin itself as the major cations in the groundwater sample exchanged for the $\mathrm{H}^{+}$ions on the resin and was, therefore, similar to preadjustment of the water sample to $\mathrm{pH} 2$.$) When the \mathrm{pH}$ of the feed solution was near neutral, significant proportions of the Pu(III), Pu(IV), and Pu(IV)-colloid samples were retained by the anion exchange resins. These data indicate that the plutonium species did not exist as the free cations prior to passage through the ion exchange columns but, rather, that the plutonium had undergone some hydrolys is and/or complexation reactions with inorganic anions. The lowering of the $\mathrm{pH}$ of the feed solution, either prior to addition to the ion exchange column or by $\mathrm{H}^{+}$ions released from the columns, reduced this effect of complexing with hydroxide or other anions. This type of action causes the greater retention of these plutonium oxidation states by the cation resin at the lower feed solution $\mathrm{pH}$. This likely also explains the greater retention of the $\mathrm{Pu}^{+6}$ oxidation state at the lower pH. However, for this oxidation state, the tendency to form an anionic plutonium complex in neutral solutions or in $\mathrm{pH} 2$ solutions is less pronounced than for the other two oxidation states. These data show the most effective concentration of these three plutonium states by ion exchange resin from groundwater solutions can be obtained if the groundwater solutions are first adjusted to $\mathrm{pH} 2$, or if the $\mathrm{H}^{+}$form of the cation resin is used. The $\mathrm{pH}$ adjustment 
achieved by either of the methods reduces the effects of complexing by inorganic anions and likely alters the naturally occurring distribution of the Pu species.

The retention of the $\mathrm{Pu}^{+_{4}}$-colloid solution by the ion exchange resins was generally poor. The anion resins did exhibit better retention characteristics than the cation resins which were examined. However, it is expected that under normal field conditions, much of the $\mathrm{Pu}^{{ }^{+}}{ }_{4}$-colloid in natural waters would not interact strongly with the ion exchange resins and would pass through such resins if they were used in the large volume water sampler. Therefore, it is necessary to back-up the ion exchange resin beds in the large volume water sampler with sorption media such as $\mathrm{Al}_{2} \mathrm{O}_{3}$ to remove the colloid from the water samples.

In summary, it appears that the most successful use of ion exchange resins for preconcentrating individual plutonium species in natural waters would be the use of the standard cation resin $(A G-50-X 4)$ in the $\mathrm{H}^{+}$form and the standard anion resin (AG 1-X4) in the $\mathrm{Cl}^{-}$form, and preadjust the $\mathrm{pH}$ of the feed solution to approximately 1.5-2. Although the macroporous resins do show good selectivity for some of the plutonium oxidation states, these materials are not presently avallable in the large quantities necessary for use with the large volume water sampler.

\section{Concentration of Al! Plutonium Species}

It has been reported that several different plutonium oxidation states can be loaded nonselectively onto cation ion exchange resin and then seiectiveiy eluted with different normalities of $\mathrm{HCl}$. (21) We evaluated this technique to determine $i$ ts usefulness with the large volume water sampler. We eluted each of the loaded resins discussed above with two aliquots of five different $\mathrm{HCl}$ normalities. The plutonium eluted in each of these 10 fractions for 22 different resin columns was determined, and the data for these elution studies are presented in Table 4.

The elution of these plutonium species from the cation res in (AG-50W-X4) in the $\mathrm{H}^{+}$form was somewhat different than had been anticipated based upon literature information. (21) A major amount of $\mathrm{Pu}^{+3}, \mathrm{Pu}^{+4}$, and $\mathrm{Pu}^{+6}$ was eluted by the first al iquot of $2.25 \mathrm{~N} \mathrm{HCl}$. The $\mathrm{Pu}^{+6}$ species, thus, were bound to the resin approximately as strongly as were the $\mathrm{Pu}^{+3}$ and $\mathrm{Pu}^{+4}$ forms. None of these forms were iikely pure aqua ions but were instead hydrolysis products and/or inorganic complexes of the cation. A more appropriate choice of eluant normalities for these step-gradient elution techniques would have been in the $0.5-2.0 \mathrm{~N} \mathrm{HCl}$ range. 
Thus, these data are not conclusive because they do not provide the desired separations. However, this type of approach--loading as large a fraction of all plutonium species onto an ion exchange resin as possible and eluting with varying $\mathrm{HCl}$ normalities--is a technique which may be improved and may be developed to the point where it can be utilized under field conditions for preconcentration and analysis of trace plutonium concentrations in natural waters.

\section{FIELD TESTING THE LARGE VOLUME WATER SAMPLING METHODOLOGY}

The Battelle large volume water sampler employing $3.0 \mu$ glass fiber filters, $0.04 \mu$ microporous polypropylene filters, and three one-half inch beds of $\mathrm{Al}_{2} \mathrm{O}_{3}$, has been field tested at several wells. These have included three wells in the 200 East area and five wells in the 200 West area of the U. S. Department of Energy Hanford Reservation. A background well l located off the Hanford Reservation has also been sampied. The analytical data obtained by these samplings is being prepared by S. M. Price, M. K. Additon, and W. C. Weimer for publication under the title, "Large Volume Water Sampling of Wells in the Vicinity of Z-Plant."

\section{CONCLUSIONS}

The results of the laboratory and field investigations to evaluate and specify methodologies for preconcentration and analysis of individual plutonium species from natural waters are summarized as follows:

1) The use of polypropylene microporous filters (pore size, 0.041) in con-

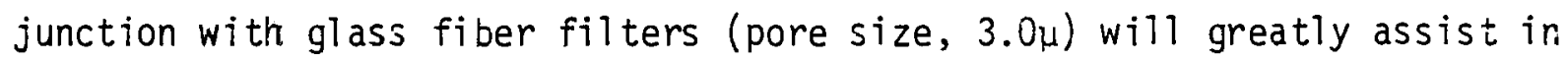
characterizing the physical/chemical nature of some of the plutonium in groundwater samples by providing particle size distribution data.

2) $\mathrm{AT}_{2} \mathrm{O}_{3}$ is by far the most effective sorption media evaluated for removing all of the plutonium species from natural water samples at near neutral pH values. The highly effective and relatively unselective ability of $\mathrm{Al}_{2} \mathrm{O}_{3}$ to concentrate plutonium makes this media useful for determining the total concentrations of soluble plutonium species in natural water samples.

3) None of the 20 sorption media examined was effective in selectively removing an individual plutonium species from the natural water samples evaluated; the ion exchange resins examined did show some preferential removal or release of individual plutonium oxidation states. Research with these resins and natural water samples has not proceeded far enough to allow the complete evaluation of their potential. 
4) A large volume water sampler fitted with two sets of filters (glass fiber and microporous polypropylene) and three one-half inch beds of $\mathrm{Al}_{2} \mathrm{O}_{3}$ is recommended for the routine collection and analysis of natural water samples containing very low concentrations of plutonium. This methodology allows the differentiation of the plutonium in the water sample into two size fractions ( $>3.0 \mu$ and $0.04-3.0 \mu$ ), microparticulate plus colloidal species (under some conditions), and soluble plutonium species.

5) For special situations where a knowledge of the charge characteristics of the soluble plutonium or the nature of the plutonium oxidation states is important, the use of ion exchange resin beds is recommended. For charge characteristics information, two one-half inch beds of cation resin $\left(\mathrm{H}^{+}\right.$form), two one-half inch beds of anion resin ( $\mathrm{Cl}^{-}$form) and three one-half inch $\mathrm{Al}_{2} \mathrm{O}_{3}$ beds are recommended. The cation exchange res in beds may be eluted with varying normalities of acid to remove individual plutonium oxidation states. While this second technique has not been adequately evaluated at this time, it may be developed for future use.

6) The water sampling method should include a final step in which at least a 10-gallon aliquot of the effluent from the sorption media or ion exchange resin beds is collected, concentrated by evaporation, and analyzed for total plutonium content. This step will assure accountability for all plutonium in the water samples.

\section{RECOMMENDATIONS}

Several recommendations for additional laboratory studies regarding the definition of the plutonium species interacting with chosen solid media and an additional field study are listed below:

1) There is a probability that very small sized particles can be transported through aquifer systems. If these small particles have plutonium attached to them by some physical/chemical mechanism, then it would appear that soluble plutonium species were moving when in fact they were not. The size of particles which can be transported and a determination of the aquifer characteristics which allow such transport should be performed. Additionally, the effectiveness for microporous polypropylene filters or other ultrafiiters to retain very fine particles which may be transported in aquifers must be evaluated. Appropriate modifications of the standard water sampling methodology can then be made so that these fine particulates are collected and characterized as such. 
2) The use of ion exchange resins to preconcentrate soluble transuranics must be evaluated in more detail. These evaluations should take two approaches. First, more laboratory work is necessary to define the optimum nornalities of $\mathrm{HCl}$ to elute different plutonium oxidation states selectively from the cation resin; and second, a better definition of those species interacting with either anionic or cationic resins is required, together with a characterization of species that, under some natural water conditions, may be retained by either resin.

3) Considerable research remains to be performed concerning the characterization of the interactions of plutonium-organic ion, plutonium-inorganic ion complexes, and plutonium-inorganic ion pairs with natural soil materials, ion exchange resins, and adsorbent media at neutral, slightly acidic, and slightly basic pH values. These investigations combined with the investigation of transuranic leachings from crib soils will provide the maximum ability to predict potential transuranic migration from nuclear waste disposal sites.

4) Additional field use of one of the proposed sampling methodologies is required to determine whether trace quantities of plutonium are migrating in aquifers underlying waste disposal trenches or cribs. Such investigations should involve sampling groundwater monitoring wells placed radially out from known locations of plutonium disposal. The sampling of a complete grid of wells surrounding a disposal site will allow the determination of what, if any, plutonium forms are moving in the aquifer and the estimation of the rates of movement. 


\section{ACKNOWLEDGEMENTS}

Much appreciation is expressed to C. L. Nelson, C. Veverka, Jr., and J. C. Kutt who performed most of the laboratory work and assisted admirably during field testing of the large volume water sampling methods. 
1. Anderson, J. D. 1976. Input and Decayed Values of Radioactive Liquid Wastes Discharged to the Ground in the 200 Areas Through 1975. ARH-CD-745.

2. Meyer, G. L. 1976. Preliminary Data on the Occurrence of Transuranium Nuclides in the Environment at the Radioactive Waste Burial Site, Maxey Flats, Kentucky. In: Transuranium Nucl ides in the Environment. Int. Atomic Energy Agency. Vienna, $724 \mathrm{p}$.

3. Bondietti, E. A. and S. A. Reynolds. 1976. Field and Laboratory Observations on Plutonium Oxidation States. In: Proceedings of an Actinide-Sediment

Reactions Working Meeting at Seattle, Washington on February 10-11, 1976. L. L. Ames, ed. BNWL-2117. Battelle, Pacific Northwest Laboratories, Richland, Wash. 99352.

4. Bondietti, E. A., S. A. Reynolds and M. H. Shanks. 1976. Interaction of Plutonium with Complexing Substances in Soils and Natural Waters. In: Transuranium Nuclides in the Environment. Int. Atomic Energy Agency, Vienna, 724 p.

5. Baes, C. F., Jr. and R. E. Mesmer. 1976. The Hydrolysis of Cations, John Wiley and Sons, New York, $489 \mathrm{p}$.

6. Wilhite, E. L. 1976. Movement of Organically Bound Plutonium in Soil. In: Proceedings of an Actinide-Sediment Reactions Working Meeting at Seattle, Washington on February 10-11, 1976. L. L. Ames, ed. BNWL-2117. Batte11e, Pacific Northwest Laboratories, Richland, Wash. 99352.

7. Weiss, A. J., A. J. Francis and P. Colombo. 1977. Characterization of Trench Water at the Maxey Flats Low-Level Radioactive Waste Disposal Site.

BNL-NUREG-22838. Brookhaven National Laboratory, Upton, New York.

8. Emery, R. M., D. C. Klopfer, T. R. Garland and W. C. Weimer. 1976. The Ecological Behavior of Plutonium and Americium in a Freshwater Ecosystem. In: Radioecology and Energy Resources. C. E. Cushing, Jr., ed. Dowden, Hutchinson and Ross, Inc., Stroudsburg, Penn. 401 p.

9. Alberts, J. A., M. A. Wahlgren, D. M. Nelson and P. J. Jehn. 1977. Submicron Particle Size and Charge Characteristics of $239,240 \mathrm{Pu}$ in Natural Waters. Environ. Sci. Tech. 11, pp. 673-676.

10. Robertson, D. E. and R. W. Perkins. 1974. Isotope Ratios as Pollutant Source and Behavior Indicators. IAEA-SM-191/24. Int. Atomic Energy Agency. Vienna.

11. Reference deleted.

12. Silker, W. B., R. W. Perkins and H. G. Rieck. 1971. A Sampler for Concentrating Radionuclides from Natural Waters. Ocean Eng. 2, pp. 49-55.

13. Silker, W. B. 1975. Collection and Analyses of Radionuclides in Sea Water. In: Analytical Methods in Oceanography. American Chemical Society, Advances in Chemistry Series, Washington, D.C. 
14. Weimer, W. C., K. H. Abel and C. I. Gibson. 1974. Biogeochemical Studies of Plutonium and Americium in the Enewetak Marine Environment. BNWL-1950

Pt. 2. Battelle, Pacific-Northwest Laboratories, Richland, Wash. 99352.

15. Cushing, C. E., D. G. Watson, D. E. Robertson and W. B. Silker. 1974. Decline of Radioactivity in the Columbia River-McNary Reservoir Ecosystem Following Shutdown of Hanford Reactors. BNWL-1850 Pt. 2. Battelle, Pacific-Northwest Laboratories, Richland, Wash. 99352.

16. Gibson, C. I., K. H. Abel, D. E. Robertson, R. L. Schmidt, T. 0. Thatcher and D. S. Trent. 1974. Biological Availability and Effects of Effluents from Coastal Nuclear Power Plants-Research Plan and Initial Efforts. BNWL-1950 Pt. 2. Battelle, Pacific-Northwest Laboratories, Richland, Wash. 99352.

17. Emery, R. M., D. C. Klopfer and W. C. Weimer. 1974. The Ecological Behavior of Plutonium and Americium in a Freshwater Ecosystem: Phase I. Limnological Characterization and Isotope Distribution. BNWL-1867. Battelle, PacificNorthwest Laboratories, Richland, Wash. 99352.

18. Cleveland. J. M. 1970. The Chemistry of Plutonium. Gordon and Breach Science Publishers.

19. Polzer, W. L. 1971. Solubility of Plutonium in Soil/Water Environments. In: Proc. of Rocky Flats Symp. on Safety in Plutonium Handling Facilities. USAEC Symp. Ser. CONF-710401. Dow Chem. Co., Rocky Flats Div., Golden, Colo.

20. Rai, D. and R. J. Serne. 1977. Plutonium Activities in Soil Solutions and the Stability and Formation of Selected Plutonium Minerals. J. Environ. Qual. 6, pp. 89-95.

21. Sprecht, V.W. and G. Hühlein. 1969. Die Säulenchromatographische Trennung der Plutonium 0xidationsstufen an dem System AG 50x8/HCl. Radiochim. Acta. 12, pp. 38. 
FIGURE 1.

\section{SCHEMATIC OF BATTELLE LARGE VOLUME WATER SAMPLER}

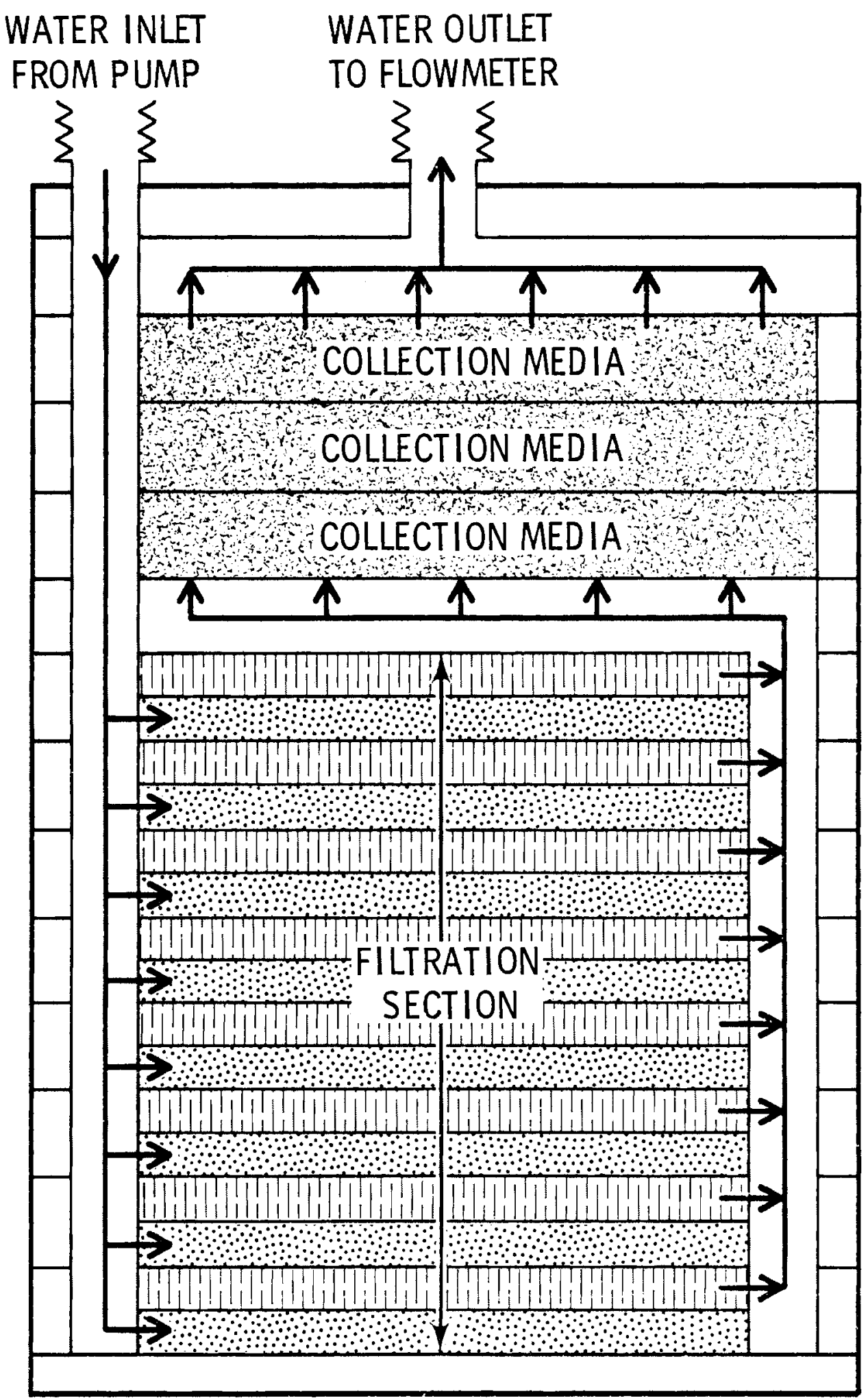


TABLE 1

LABORATORY INVESTIGATION OF MICROPOROUS FILTER FLOW RATES

\begin{tabular}{|c|c|c|c|c|}
\hline \begin{tabular}{c}
\multicolumn{2}{c}{ Celgard } \\
Filter Type \\
\end{tabular} & Pore Size- $\mu$ & $\begin{array}{l}\text { Orientation to } \\
\text { Water Flow } \\
\end{array}$ & $\begin{array}{c}\text { Estimated Fl } \\
\text { Eight Large } \\
\text { Sampler } \\
\text { (Connected } \\
\end{array}$ & $\begin{array}{l}\text { ow Rate Througl } \\
\text { Volume Water } \\
\text { ilter Plates } \\
\text { in Parallel)* }\end{array}$ \\
\hline 3400 & 0.02 & Both sides slick & 42 & $\mathrm{ml} / \mathrm{min}$ \\
\hline 3401 & 0.02 & $" 11$ & 22 & $"$ \\
\hline 3500 & 0.04 & 11 & 417 & $"$ \\
\hline 3501 & 0.04 & 111 & 216 & $"$ \\
\hline 5410 & 0.02 & Dull side & 353 & $"$ \\
\hline 5410 & 0.02 & slick side & 78 & $"$ \\
\hline 5411 & 0.02 & Dult side & 259 & $"$ \\
\hline 5411 & 0.02 & slick side & 133 & $"$ \\
\hline 5510 & 0.04 & Dull side & 293 & $"$ \\
\hline 5510 & 0.04 & slick side & 176 & 11 \\
\hline 5511 & 0.04 & Dull side & 505 & 11 \\
\hline 5511 & 0.04 & Slick side & 425 & $\prime \prime$ \\
\hline
\end{tabular}

* Flow rates extrapolated from measurement of flow rate through a single $4 \mathrm{~cm}$ diameter filter. 
PLUTONIUM LOADING ONTO ADSOREENT MEDIA FRON NEUTRAL GROUNDWATER SOLUTIONS

Percent of Individual Pu Species Retained

Adsorbent Media

$\mathrm{Al}_{2} \mathrm{O}_{3}$, neutral, WBS, \#27828

$\mathrm{Al}_{2} \mathrm{O}_{3}$, neutral, \#2087 (70-290 mesh)

$\mathrm{AT}_{2} \mathrm{O}_{3}$, acid, \#2102 (70-290 mesh)

$\mathrm{Al}_{2} \mathrm{O}_{3}$, basic, \#2072 (70-290 mesh)

Silica Gel, \#2747

Silica Gel, \#2753

Silica Gel, Type 205, \#2810 (30-70 mesh)

Silica Gel, Type 207, \#4651 (150-230 mesh)

Silica Gel, Type 204, \#4662 (70-230 mesh)

$\mathrm{SiO}_{2} \cdot \times \mathrm{H}_{2} \mathrm{O}$ (100 mesh)

Chromosorb A (60-80 mesh)

Chromosorb G (60-80 mesh)

Chromosorb 101 (60-80 mesh)

Chromosorb W, NAW (80-100 mesh)

Chromosorb, W, AW, DCMS (80-100 mesh)

Florisil (100-200 mesh)

Polyamide, \#3284

Cellex $\mathrm{N}-\mathrm{T}$, non-ionic cellulose

Chelex 100 (100-200 mesh)

Zirconium Pinosphate RC-24 (>50 mesh) by Adsorbent

\begin{tabular}{|c|c|c|c|c|}
\hline \multicolumn{2}{|c|}{$\mathrm{Pu}^{+3^{2}}$} & \multirow{2}{*}{$\frac{\mathrm{Pu}^{+4}}{81}$} & \multirow{2}{*}{$\frac{\mathrm{Pu}^{+6}}{104}$} & \multirow{2}{*}{$\frac{\mathrm{Pu}^{+4}}{\text { Colloid }}$} \\
\hline 82 & 101 & & & \\
\hline 95 & 91 & 85 & 101 & 93 \\
\hline 89 & 83 & 88 & 99 & 85 \\
\hline 85 & 80 & 89 & 98 & 74 \\
\hline 48 & 26 & 49 & 51 & N.D. \\
\hline 76 & 53 & 68 & 54 & 67 \\
\hline 13 & 26 & 26 & 35 & 26 \\
\hline 68 & 52 & 71 & 50 & 76 \\
\hline 58 & 30 & 55 & 47 & 62 \\
\hline 72 & 46 & 74 & 53 & N.D. \\
\hline 37 & 29 & N.D. & 40 & 13 \\
\hline 35 & 31 & 20 & 35 & 19 \\
\hline$-2^{2}$ & $--^{2}$ & $--^{2}$ & $-^{2}$ & $--^{2}$ \\
\hline 37 & 19 & 26 & 35 & 46 \\
\hline$--^{2}$ & $--^{2}$ & $--^{2}$ & $-^{2}$ & $--^{2}$ \\
\hline 82 & 67 & 68 & 69 & 63 \\
\hline 52 & 37 & 32 & 38 & 47 \\
\hline 64 & 53 & 40 & 51 & 48 \\
\hline 18 & 24 & 20 & 43 & 24 \\
\hline 15 & 14 & 20 & 33 & 34 \\
\hline
\end{tabular}

1 Duplicate experiments were performed.

2 Adsorbent media floats 


\section{TABLE 3}

\section{PLUTONIUM LOADING ONTO ION EXCHANGE RESINS FROM GROUNDWATER SOLUTIONS}

Percent of Individual Pu Species Retained by Ion Exchange Resins

Resin

AG-50W-X 4 (50-700 mesh) $\mathrm{Na}^{+}$form $A G-50 W-X 4$ (50-700 mesh) $H^{+}$form AG MP-50 (50-100 mesh) $\mathrm{Na}^{+}$form AG MP-50 (50-100 mesh) $\mathrm{H}^{+}$form AG 1-X4 (50-100 mesh) $\mathrm{Cl}^{-}$form AG MP-1 (50-100 mesh) $\mathrm{Cl}^{-}$form

$A G-50 W-X 4$ (50-100 mesh) $\mathrm{Na}^{+}$form $A G-50$ W-X4 (50-100 mesh) $H^{+}$form AG MP-50 (50-100 mesh) $\mathrm{Na}^{+}$form AG MP-50 (50-100 mesh) $\mathrm{H}^{+}$form $A G$ T-X4 (50-100 mesh) $\mathrm{Cl}^{-}$form AG MP-1 (50-100 mesh) $\mathrm{Cl}^{-}$form

$$
\underline{\mathrm{Pu}}+3
$$$$
\underline{\mathrm{Pu}^{+4}}
$$$$
\underline{\mathrm{Pu}^{+6}}
$$

FEED SOLUTION $\mathrm{pH}: 7$

38

$$
22
$$

29

30

43

30

78

36

59

77

54

55

FEED SOLUTION $\mathrm{pH}: 2$

$\begin{array}{ll}59 & 59 \\ 76 & 54 \\ 74 & 60 \\ 93 & 70 \\ 44 & 66 \\ 47 & 64\end{array}$

64

85

62

84

20

24
N.D.

N.D.

N.D.

N.D.

N.D.

28

N.D.

N.D.

46

63

62

N.D. 
TABLE 4

ELUTION OF PLUTONIUM SPECIES FROM ION EXCHANGE RESINS

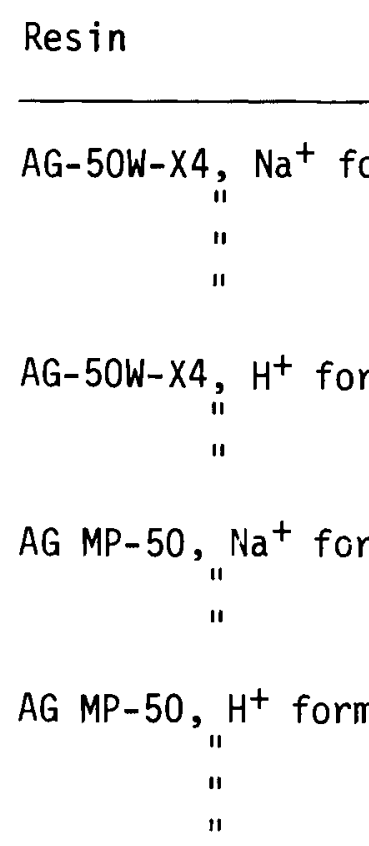

AG $1-X 4, C 1-$ form

$$
"
$$

AG MP- $1, \mathrm{Cl}^{-}$form$$
\text { " }
$$

1 Not detectable

\section{Percent Pu Eluted}

\begin{tabular}{l} 
Pu Valence State \\
\hline+3 \\
+4 \\
+6 \\
+4, colloid
\end{tabular}

\begin{tabular}{rr}
\hline 0.2 & $\mathrm{~N} \mathrm{HCl}$ \\
1 & 2 \\
\hline .7 & .7 \\
.9 & .2 \\
6.2 & --1 \\
2.8 & 4.4
\end{tabular}

\begin{tabular}{rr}
0.5 & $\mathrm{~N} \mathrm{HCl}$ \\
1 & 2 \\
\hline 1.2 & 1.7 \\
.4 & .3 \\
1.6 & 1.7 \\
-- & --
\end{tabular}

\begin{tabular}{cc}
1.0 & $\mathrm{~N}$ \\
$\mathrm{i}$ & $\mathrm{HCl}$ \\
\hline 6.6 & 7.1 \\
4.1 & 4.5 \\
5.3 & 7.6 \\
-- & -- \\
& \\
8.1 & 7.0 \\
3.5 & 3.0 \\
5.6 & 7.3 \\
-- & .7 \\
.2 & .2 \\
.1 & -- \\
-- & .4 \\
1.0 & .6 \\
.1 & .3 \\
9.3 & 2.7
\end{tabular}

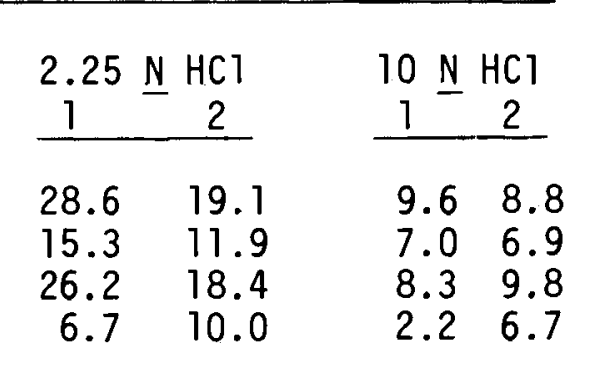

Pent Remining on Resin

18.6

10.5
15.1

15.1

$\begin{array}{lllr}32.7 & 20.4 & 9.8 & 10.1 \\ 14.2 & 12.0 & 7.2 & 9.0\end{array}$

18.7

$\begin{array}{rrrrrrrr}.2 & .3 & 1.0 & 1.0 & 8.1 & 7.0 & 32.7 & 20.4 \\ 1.0 & -- & 1.0 & .6 & 3.5 & 3.0 & 14.2 & 12.0 \\ 1.2 & -- & 1.2 & .9 & 5.6 & 7.3 & 26.3 & 18.9\end{array}$

$\begin{array}{rr}7.2 & 9.0 \\ 9.7 & 12.9\end{array}$

13.3
21.3

$\begin{array}{llll}.4 & -- & .2 & .3 \\ .1 & .2 & -- & .2 \\ -- & -- & .2 & --\end{array}$

$\begin{array}{ll}1.6 & 2.0 \\ 1.3 & 1.5 \\ 1.4 & 1.8\end{array}$

$\begin{array}{lll}54.8 & 30.4\end{array}$

$\begin{array}{ll}31.8 & 18.4 \\ 60.2 & 26.1\end{array}$

21.3
12.9
19.5

$\begin{array}{lll}57.7 & 29.5 \\ 43.3 & 14.9\end{array}$

54.930 .4

$\begin{array}{lll}54.9 & 30.4 \\ 34.7 & 74.7\end{array}$

20.5

9.8

22.7
10.7

\section{$1.7 \quad 3.4$}

$\begin{array}{rr}2.2 & .7 \\ 2.5 & .8 \\ 23.1 & 7.3\end{array}$

5

+3
+4
+6

+6
+4 , colloid

$\begin{array}{lr}.5 & -- \\ 1.5 & 3.3 \\ 6.7 & 4.6 \\ 3.5 & --\end{array}$

$\begin{array}{rr}2.8 & 4.4 \\ 10.1 & 11.5\end{array}$

$\begin{array}{rr}10.7 & 11.5 \\ 1.0 & 11.5\end{array}$

$\begin{array}{rrrr}31.4 & 24.2 & 26.3 & 2.7 \\ 30.9 & 26.7 & 16.8 & 1.7 \\ 10.6 & 7.1 & 5.5 & 2.4\end{array}$

3.9

3.9
1.5
.2
--

$\begin{array}{rrrr}7.3 & 1.3 & 2.2 & 1.4 \\ 12.6 & 4.1 & 4.5 & 3.1 \\ 14.5 & 4.7 & 4.7 & 3.3 \\ 8.0 & 14.0 & 14.0 & -.\end{array}$

$\begin{array}{ll}4.1 & 6.5 \\ 4.9 & 5.9\end{array}$

$\begin{array}{ll}4.9 & 5.9 \\ 6.3 & 4.1\end{array}$

$\begin{array}{rr}6.3 & 4.1 \\ -- & 16.5\end{array}$

$\begin{array}{rrrr}24.6 & 24.3 & 28.3 & .4 \\ 13.9 & 10.9 & 13.1 & 1.0\end{array}$

$\begin{array}{llll}14.8 & 12.0 & 12.0 & .5\end{array}$
Percent Pu Recovered

103
62
100
34

109
65
105
112
67
109
110
77
113
80
97
93
90
90
103
79
79
53




\section{DISTRIBUTION}

No. of

Copies

OFFSITE

A. A. Churm Department of Energy Chicago Patent Group 9800 South Case Avenue Argonne, IL 60439

27 Technical Information Center

Department of Energy Washington, DC 20545
No. of

Copies

ONSITE

DOE, Richland Operations office

H. E. Ransom

Battelle-Northwest

J. M. Nielsen

R. W. Perkins

W. D. Felix

D. E. Robertson

K. H. Abel

P. A. Eddy

J. C. Kutt

C. L. Nelson

C. Veverka, Jr.

W. C. Weimer (10)

Technical Information Library (5)

Publishing Coordination (2)

Rockwe 11 Hanford Operations

Rockwell Hanford Operations Document Control

(2)

M. K. Additon

R. B. Kasper

A. G. Law

S. M. Price

W. H. Price

R. M. Smith 


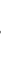

